\title{
Do patients with chronic rhinosinusitis with nasal polyps suffer with facial pain? *
}

\author{
Ahmed Z. Eweiss' ${ }^{1,2}$, Valerie J. Lund', Johanna Barlow \\ ' Royal National Throat Nose and Ear Hospital, London, United Kingdom \\ ${ }^{2}$ Department of Otolaryngology, Faculty of Medicine, University of Alexandria, Egypt
}

Rhinology 51: 231-235, 2013

DOI:10.4193/Rhino12.087

*Received for publication:

May 21, 2012

Accepted: February 22, 2013

\begin{abstract}
Summary
Background: Many patients attribute their symptoms of facial pain or headache to sinus problems. Facial pain is one of the symptoms of rhinosinusitis according to European and American consensus documents. This symptom, however, has been insufficiently studied in the group of patients with chronic rhinosinusitis with nasal polyps (CRSwNP). The aim of this work is to study the symptom of facial pain in patients with CRSwNP.
\end{abstract}

Methods: Patients with CRSwNP were prospectively asked to score their facial pain according to the scoring system used in the Sino Nasal Outcome Test 22 (SNOT 22).

Results: Fifty patients fulfilled the inclusion criteria. Thirty-one patients had grade II polyps and 19 patients had grade III polyps. Of these patients, $76 \%$ had absent or very mild facial pain. Only $16 \%$ of patients had moderate or severe facial pain. All patients with severe facial pain had viscid secretions within their sinuses.

Conclusion: Significant facial pain is uncommon in patients with CRSwNP. It is important to consider this when counselling patients before surgery.

Key words: chronic rhinosinusitis, nasal polyps, facial pain

\section{Introduction}

Sinonasal polyps are oedematous structures that most commonly originate in the middle meatus, and protrude into the nasal cavity as a result of a chronic inflammatory process of the sinonasal mucosa ${ }^{(1,2)}$. The word "polyp" is derived from the Greek word "poly-pous" meaning many-footed ${ }^{(3)}$. The prevalence of sinonasal polyps within the general population has been estimated to be $1-4 \%$, and the incidence generally increases with age $^{(4,5)}$.

According to the European consensus document published in 2012, sinonasal polyps are included within a broad definition of rhinosinusitis, as chronic rhinosinusitis with nasal polyps $(\text { CRSwNP) })^{(6)}$. Rhinosinusitis in general is considered when the patient presents with 2 or more symptoms, one of them should be either nasal blockage or discharge +/- facial pain and +/loss of smell. Endoscopic and/or CT signs of rhinosinusitis are required for a clinical diagnosis but are not essential for an epidemiological study or a general practice diagnosis ${ }^{(6)}$. Similarly, the diagnosis of rhinosinusitis according to the American Academy of Otolaryngology-Head and Neck Surgery (AAO-HNS) depends on the presence of 2 or more of 4 symptoms including nasal blockage, nasal/postnasal discharge, facial pain and smell 
loss, with documented inflammation by nasendoscopic and/or radiological findings ${ }^{(7)}$.

Although the above documents give clear guidance to the clinical presentation of rhinosinusitis in general, very few studies have attempted to record the symptoms of patients with CRSwNP as a separate group. In the current study, we have focussed on the symptom of facial pain as experienced by patients with CRSwNP.

\section{Material and methods}

\section{Study population / Sino Nasal Outcome Test 22}

Patients with CRSwNP attending the outpatients department, or admitted for surgery in a tertiary referral centre in London, UK, were prospectively assessed. All patients were asked to report their symptom of facial pain/pressure over the 2 weeks prior to and including the day of the assessment, using the symptom scoring system of the Sino Nasal Outcome Test 22 (SNOT 22) ${ }^{(8)}$ where:

$0=$ no symptom

$1=$ very mild symptom

$2=$ mild symptom

$3=$ moderate symptom

4= severe symptom

$5=$ symptom as bad as it can be

The SNOT 22 test does not require the patients to provide details regarding their facial pain apart from the severity of pain. No information is sought regarding the character or distribution of the facial pain. We deliberately avoided enquiring the patients about these details as the aim of the study was not to classify the type of facial pain, or to investigate the dilemma of whether the pain was related to the sinonasal condition or not. The aim was rather to report the presence of any form of facial pain and its severity in patients with CRSwNP. This is in accordance with the definition of chronic rhinosinusitis agreed upon in the European position document ${ }^{(6)}$ which deliberately made no specifications for the characteristics of facial pain to avoid confusion in the diagnosis of rhinosinusitis.

\section{Procedures}

Nasal endoscopic examination using 0 degree $4 \mathrm{~mm}$ rigid telescopes was performed on all patients to diagnose CRSWNP. Patients with grade I sinonasal polyps according to the system published by Mackay and Lund ${ }^{(9)}$ (polyps only lateral to the middle turbinate in the middle meatus) were excluded from the study. This was decided as these patients may represent a different clinico-pathological group from those with more advanced grades of sinonasal polyps. All patients with grade II or more sinonasal polyps were included consecutively in the study, with no other exclusion criteria.
All patients included were receiving a daily dose of 800 microgram Fluticasone propionate nasal drops at the time of the study, which is a standard regimen prescribed for patients with CRSwNP in our department.

\section{Statistical analysis}

The Chi Square Test with Yates' correction at 5\% level of significance was used to assess the difference in the incidence of pain between different subgroups of patients. Pearson correlation was used to assess the correlation between pain scores and other SNOT 22 scores.

\section{Ethical statement}

Ethics approval was not required for this study as it is our routine practice to ask patients to fill a SNOT 22 form when attending the outpatients department or being admitted for surgery. This study did not incorporate any form of extra examination or investigation above what we would normally arrange for patients not included in any studies. Hence, specific ethics approval and patients' consent were not applicable for this type of study.

\section{Results}

Fifty patients fulfilled the inclusion criteria over the study period. Among them, there were 31 males (62\%) and 19 females (38\%). The age ranged from $16-73$ years with a mean of $48.9(+/-12.9)$ years.

Thirty-one patients had grade II polyps, and 19 patients had grade III polyps. Thirty-five patients (70\%) suffered with asthma, and 19 patients (38\%) also had aspirin sensitivity (Samter's triad) $(10,11)$. Thirty-nine patients (78\%) were the subjects of previous surgical procedures for their polyps. These procedures were either simple polypectomy or endoscopic sinus surgery. None of the patients had previously been exposed to any forms of external sinus surgery. The number of previous procedures per patient ranged from 1-18.

Figure 1 demonstrates the prevalence of the above conditions among the studied population.

The scores of facial pain reported by the 50 patients are summarised in Table 1.

The mean total SNOT 22 score for the included patients was 49.46. Nasal blockage was the SNOT 22 item with the highest mean score (4.62), followed by loss of smell/ taste (4.39). Among the 3 patients with severe or extreme facial pain, 2 patients had grade II polyps, and 1 patient had grade III polyps. Among the 5 patients with moderate facial pain, 2 patients had grade II polyps, and 3 patients had grade III polyps.

All 3 patients with severe or extreme facial pain were found to have viscid mucous secretions within their paranasal sinuses. In 
Table 1. Scores of facial pain reported by 50 patients with grades II / III sinonasal polyps.

\begin{tabular}{lccc|}
\hline $\begin{array}{l}\text { Facial pain } \\
\text { score }\end{array}$ & $\begin{array}{c}\text { Total number } \\
\text { of patients }\end{array}$ & $\begin{array}{c}\text { Number of } \\
\text { patients with } \\
\text { grade II } \\
\text { polyps }\end{array}$ & $\begin{array}{c}\text { Number of } \\
\text { patients with } \\
\text { grade III } \\
\text { polyps }\end{array}$ \\
\hline 0 : no pain & $28(56 \%)$ & $19(38 \%)$ & $9(18 \%)$ \\
\hline $\begin{array}{l}\text { 1: very mild } \\
\text { pain }\end{array}$ & $10(20 \%)$ & $5(10 \%)$ & $5(10 \%)$ \\
\hline $\begin{array}{l}\text { 2: mild pain } \\
\text { 3: moderate } \\
\text { pain }\end{array}$ & $4(8 \%)$ & $3(6 \%)$ & $1(2 \%)$ \\
$\begin{array}{l}\text { 4: severe pain } \\
\text { 5: extreme pain } \\
\text { (as bad as it } \\
\text { can be) }\end{array}$ & $1(10 \%)$ & $2(4 \%)$ & $3(6 \%)$ \\
\hline
\end{tabular}

one of them, the secretions were suggestive morphologically of eosinophilic fungal sinusitis, but there was no subsequent histological or microbiological proof of fungal hyphae.

In 2 out of the 5 patients with moderate facial pain (40\%), viscid secretions were also identified in the paranasal sinuses. In one of them, the secretions were purulent, and in the other patient, eosinophilic fungal sinusitis was proven histologically. None of the 28 patients who did not suffer with pain were found to have viscid or purulent sinus secretions. Similarly, none of the 4 patients who described mild degree of pain had secretions from their paranasal sinuses. Only 1 patient among the 10 describing very mild pain (10\%) was found to have purulent secretions from the paranasal sinuses on the same side of the pain.

No significant difference was found in the incidence of pain between male and female patients.

No significant difference was found in the incidence of pain between patients with or without asthma, with and without aspirin sensitivity and with or without history of previous surgery for sinonasal polyps.

No correlation was found between facial pain scores and total SNOT 22 scores $(r=0.49, p=2.70)$, facial pain scores and nasal blockage scores $(r=0.20, p=2.70)$ or facial pain scores and loss of smell/ taste scores $(r=0.10, p=7.30)$.

\section{Discussion}

Many patients suffering from facial pain or headaches attribute their symptoms to sinus problems ${ }^{(12)}$. Cady and Schreiber commented that the American public believe deeply in the concept of sinus disease as a common cause of headache, although the

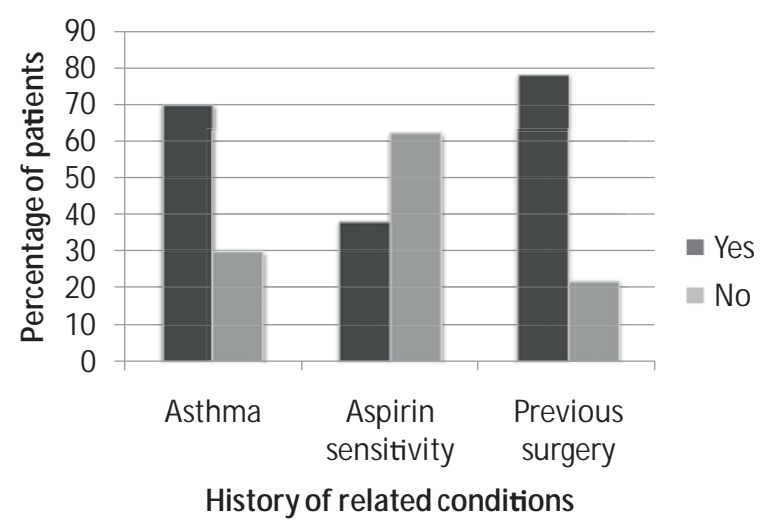

Figure 1. Prevalence of some related conditions in 50 patients with grades II / III sinonasal polyps. evidence to support this concept is limited ${ }^{(13)}$. Although acute sinusitis can present by severe facial pain, chronic sinusitis is usually painless unless associated with acute exacerbation ${ }^{(12)}$. The International Headache Society (IHS) includes acute sinusitis in its classification of the causes of headache, but does not consider chronic sinusitis to be a validated cause of headache or facial pain ${ }^{(14)}$.

Several workers have attempted to explain the "sinus pain" over the years. Sluder described frontal "vacuum headache" in the early 20th century ${ }^{(15)}$. McAuliffe and colleagues published their experiments on stimulation of the sino-nasal mucosa to study mechanisms of pain development ${ }^{(16)}$. In the modern era, Stammberger and Wolf hypothesised that mucosal contact areas within the paranasal sinuses leads to release of substance $P$, which stimulates the nociceptive receptors ${ }^{(17)}$. However, there has been no experimental work to support this theory ${ }^{(12)}$. Sluder's and McAuliffe's conclusions have also been challenged ${ }^{(12,18)}$. In recent years, several workers have shown that patients with "sinus pain", are actually, in the majority of cases, suffering from migraine or a variant of tension headache ${ }^{(12,13,19-22)}$.

Despite the various efforts to study pain with rhinosinusitis, very few attempts were made to study the pain in patients with CRSwNP as a separate group. Drake-Lee et al. reported that 35\% of patients with sinonasal polyps complained of facial pain ${ }^{(23)}$. Fahy and Jones found that only $18 \%$ of patients with sinonasal polyps suffered with facial pain. More than $60 \%$ of those suffering with pain in their study were found to have purulent secretions within their sinuses. Two thirds of the patients who had pain without purulent secretions were found to have other neurological causes for their pain ${ }^{(24)}$. 
In the current study, our results showed that $62 \%$ of the patients were males. This is in accordance with previous reports indicating a higher incidence of sinonasal polyps in males ${ }^{(23,25,26)}$. Seventy percent of the patients in the present study suffered with asthma, a higher incidence than that reported for asthma in patients with CRSwNP in previous studies, which ranged between $21-44 \%^{(23,26-28)}$. This can be attributed to the nature of our practice in a tertiary referral centre where most patients suffer with disease that has been refractory to treatment offered by other centres. The incidence of asthma in our patients corresponds to the incidence reported by workers from a specialised allergy practice, where $71 \%$ of patients with sinonasal polyps were found to suffer with asthma ${ }^{(29)}$. Similarly, the high incidence of previous surgical procedures for nasal polyps among the patients in this study (78\%) can be explained by the type of service provided by our hospital as a tertiary referral centre, where a high percentage of our patients are referred to us after failing surgical treatment elsewhere.

In the present study, $76 \%$ of the patients reported absent or very mild facial pain. A further $8 \%$ reported mild facial pain. Only $16 \%$ of the patients had moderate or severe facial pain. There was no difference in the incidence of facial pain between males and females. Similarly, presence of asthma, aspirin sensitivity or history of previous surgery for sinonasal polyps was not associated with a significant difference in the incidence of facial pain. All patients with severe facial pain had viscid secretions within their sinuses, and $40 \%$ of patients with moderate pain also had purulent secretions or eosinophilic fungal sinusitis. These findings are similar to those detected by Fahy and Jones ${ }^{(24)}$.

One limitation of the current study might be the lack of comparison with a group of patients with chronic rhinosinusitis without nasal polyps (CRSsNP). However, a number of prospective and retrospective reports studying facial pain in the latter group of patients have already been published, and thus very little can be added to the literature by studying this once more. It is possible, nevertheless, to compare our results to a historical group from previous well conducted studies. Bugten et al. ${ }^{(30)}$ detected significantly higher mean scores for facial pain and headache among patients with CRSsNP when compared to patients with CRSwNP in a prospective study. Similarly, Dudvarski et al. ${ }^{\left({ }^{11}\right)}$ reported the same findings in another prospective study, although their results did not reach statistical significance. Jakobsen and Svendstrup ${ }^{(32)}$ used the term "chronic infectious sinusitis" to describe CRSsNP, and prospectively identified an incidence of facial pain above $60 \%$ among a group of patients with this condition. In a retrospective study, Mehanna et al. ${ }^{(33)}$ found that headache was the commonest symptom among patients with CRSsNP admitted for endoscopic sinus surgery, and was present in $37 \%$ of the patients in this group. The above studies therefore showed that $37-60 \%$ of patients with CRSsNP complained of facial pain and/or headache. In comparison, our results showed that facial pain is less common in the group of patients with CRSwNP.

The current study showed that in the absence of viscid or purulent secretions from the paranasal sinuses, patients with CRSwNP rarely complain of significant degrees of facial pain. It is important to consider this finding when counselling patients before surgery for sinonasal polyps, so that their expectations regarding the improvement of their facial pain with surgery remain realistic.

\section{Conclusions}

The current study shows that significant facial pain is an uncommon symptom in patients with CRSwNP. Patients with this symptom admitted for surgery should be properly counselled to ensure they have realistic expectations regarding the improvement of their facial pain post-operatively.

\section{Authorship contribution}

AZE: Collected the data for the study, reviewed the literature and prepared the manuscript.

VJL: Originated the idea of the study and reviewed and modified the manuscript.

JB: Shared in collection of data.

\section{Conflict of interest}

The authors declare no conflict of interest.

\section{References}

1. Jankowski R. Eosinophils in the pathophysiology of nasal polyps. Acta Otolaryngol. 1996; 116: 160-163.

2. Naclerio RM, Mackay IS. Guidelines for the management of nasal polyposis. In: Mygind N, Lildholdt T, eds. Nasal polyps, an inflammatory disease and its treatment. Copenhagen : Munksgaard, 1997; 177-180.

3. Drake-Lee AB. Nasal polyps. Hosp Med. 2004; 65: 264-267.

4. van der Baan B. Epidemiology and natural history. In : Mygind N, Lildholdt T, eds. Nasal polyps, an inflammatory disease and its treatment. Copenhagen : Munksgaard, 1997; 88-97.

5. Larsen K, Tos M. The estimated incidence of symptomatic nasal polyps. Acta Otolaryngol. 2002; 122: 179-182.

6. Fokkens WJ, Lund VJ, Mullol J et al. European position paper on rhinosinusitis 
and nasal polyps 2012. Rhinology. 2012; 50; suppl 23: 1-299.

7. Rosenfield RM, Andes D, Bhattacharrya $\mathrm{N}$ et al. Clinical practice guideline: adult sinusitis. Otolaryngol Head Neck Surg. 2007; 137; suppl 3: 1-31.

8. Hopkins C, Browne J, Slack R, Gillett S, Lund $\checkmark$ Psychometric validity of the 22 item Sinonasal Outcome Test (SNOT-22). Clin Otolaryngol. 2009; 34: 447-454.

9. Mackay IS, Lund VJ. Imaging and staging. In: Mygind N, Lildholdt T, eds. Nasal polyposis: an inflammatory disease and its treatment. Copenhagen: Munksgaard, 1997; 137-144.

10. Samter M. Nasal polyps: their relationship to allergy, particularly to bronchial asthma. Med Clin N Am. 1958; 42: 175-189.

11. Samter M, Beers RF Jr. Concerning the nature of intolerance to aspirin. J Allergy. 1967; 40: 281-293.

12. Jones NS. Sinogenic facial pain: Diagnosis and management. Otolaryngol Clin N Am. 2005; 38: 1311-1325.

13. Cady RK, Schreiber CP. Sinus headache: a clinical conundrum. Otolaryngol Clin N Am. 2004; 37: 267-288.

14. Headache Classification Subcommittee of the International Headache Society. The international classification of headache disorders: 2nd edition. Cephalgia. 2004; 24 (suppl 1): 9-160.

15. Sluder G. Headaches and eye disorders of nasal origin. London: Henry Kimpton, 1919; 57-85.

16. Mcauliffe GW, Goodell H, Wolf HG. Experimental studies on headache: pain from the nasal and paranasal structures. Res Publ Assoc Res Nerv Ment Dis 1943; 23: 185-208.

17. Stammberger $H$, Wolf $G$. Headaches and sinus disease: the endoscopic approach.
Ann Otol Rhinol Laryngol. 1988; 143: 3-23.

18. Abu-Bakra M, Jones NS. Does stimulation of the nasal mucosa cause referred pain to the face? Clin Otolaryngol. 2001; 26: 403-432.

19. Schreiber CP, Hutchinson S, Webster CJ, Ames M, Richardson MS, Powers C. Prevalence of migraine in patients with a history of self reported or physician diagnosed sinus headache. Arch Intern Med. 2004; 164 : 1769-1772

20. Levine HL, Setzen M, Cady RK, Dodick DW et al. An otolaryngology, neurology, allergy and primary care consensus on diagnosis and treatment of sinus headache. Otolaryngol H N Surg. 2006; 134: 516-523.

21. Eross E, Dodick D, Eross M. The sinus, allergy and migraine study (SAMS). Headache 2007; 47: 213-224

22. Foroughipour M, Sharifian SMR, Shoeibi A, Barabad NE, Bakhshaee M. Causes of headache in patients with a primary diagnosis of sinus headache. Eur Arch Otorhinolaryngol 2011; 268: 1593-1596.

23. Drake-Lee AB, Lowe $D$, Swanson A, Grace A. Clinical profile and recurrence of nasal polyps. J Laryngol Otol. 1984; 98: 783-793.

24. Fahy C, Jones NS. Nasal polyposis and facial pain. Clin Otolaryngol. 2001; 26: 510-513.

25. Johansson L, Akerlund A, Holmberg K Melén I, Bende M. Prevalence of nasal polyps in adults: the Skovde population-based study. Ann Otol Rhinol Laryngol. 2003; 112: 625-629.

26. Hopkins C, Browne JP, Slack R, Lund V Topham J, Reeves B, Copley L, Brown P, van der Meulen J. The national comparative audit of surgery for nasal polyposis and chronic rhinosinusitis. Clin Otolaryngol. 2006: 31: 390-398.

27. Larsen K, Tos M. Clinical course of patients with primary nasal polyps. Acta
Otolaryngol. 1994; 114: 556-559.

28. Brown BL, Harner SG, vanDellen RG. Nasal polypectomy in patients with asthma and sensitivity to aspirin. Arch Otolaryngol. 1979; 105: 413-416.

29. Settipane G, Chafee F. Nasal polyps in asthma and rhinitis. A review of 6037 patients. J Allergy Clin Immunol. 1997; 59: 17-21.

30. Bugten $V$, Nordgard $S$, Romundstad $P$ Steinsvag S. Chronic rhinosinusitis and nasal polyposis; indicia of heterogeneity. Rhinology. 2008; 46: 40-44

31. Dudvarski Z, Pendjer I, Djukic V, Janosevic $L$, Mikic A. The analysis of clinical characteristics of the chronic rhinosinusitis: complicated and uncomplicated form. Eur Arch Otorhinolaryngol. 2008; 265: 923-927.

32. Jakobsen JJ, Svendstrup F. Functional endoscopic sinus surgery in chronic sinusitis - a series of 237 consecutively operated patients. Acta Otolaryngol. 2000; suppl 543: 158-161.

33. Mehanna H, Mills J, Kelly B, McGarry GW. Benefit from endoscopic sinus surgery. Clin Otolaryngol. 2002; 27: 464-471+

\section{Ahmed Z. Eweiss}

Royal National Throat Nose and Ear

Hospital

London

United Kingdom

Tel: +44-78-4982 5904

E-mail:azews@yahoo.com 